\title{
IKH TURGEN MOUNTAIN GLACIER CHANGE AND 3D SURFACE EXTENTS PREDICTION USING LONG TERM LANDSAT IMAGE AND CLIMATE DATA
}

\author{
Elbegjargal Nasanbat ${ }^{* * 3}$, Erdenetogtokh Erdenebat ${ }^{2}$, Bolorchuluun Chogsom $^{2}$, \\ Ochirkhuyag Lkhamjav ${ }^{3}$, Lkhagvadorj Nanzad ${ }^{4}$ \\ ${ }^{1}$ Information and Research Institute of Meteorology, Hydrology and Environment, Juulchiny street-5, \\ Ulaanbaatar 15160, Mongolia; n.elbegjargal@gmail.com \\ ${ }^{2}$ Department of Geography, School of Art and Sciences, National Universes of Mongolia; erdenetogtoherdenebat12@gmail.com, \\ bolorchuluun@gmail.com \\ ${ }^{3}$ Mongolian Geospatial Association, P.O. Box 24/38, Ulaanbaatar 15141, Mongolia; \\ mongeoinfo@gmail.com, ochirkhuyag@geomedeelel.mn \\ ${ }^{4}$ Institute of Remote Sensing and Digital Earth(RADI), Chinese Academy of Sciences (CAS) Dengzhuang South Road, Haidian \\ District, Beijing 100094, China; hagvaa@radi.ac.cn
}

KEY WORD: Landsat imagery, glacier, 2D, 3D area, Prediction, climate, decision-tree

\begin{abstract}
:
The glacier is most important the freshwater resources and indicator of the climate change. The researchers noted that during last decades the glacier is melting due to global warming. The study calculates a spatial distribution of protentional change of glacier coverage in the Ikh Turgen mountain of Western Mongolia, and it integrates long-term climate data and satellite datasets. Therefore, in this experiment has tried to estimation three-dimensional surface area of the glacier. For this purpose, Normalized difference snow index (NDSI) was applied to decision tree approach, using Landsat MSS, TM, ETM+ and LC8 imagery for 1975-2016, a surface and slope for digital elevation model, precipitation and air temperature historical data of meteorological station. The potential volume area significantly changed glacier cover of the Ikh Turgen Mountain, and the area affected by highly variable precipitation and air temperature regimes. Between 1972 and 2016, a potential area of glacier area has been decreased in Ikh Turgen mountain region.
\end{abstract}

\section{INTRODUCTION}

Glaciers of mountain or alpine are a part of the hydrological regime of the global and regional. Beniston (2003) noted that the glaciers could support in streams and watersheds of the locals where water is accumulated during winter season and consequently in spring runoff as melt water. Some researchers the glaciers are regarded as a valuable source of fresh water, which is considered as an important component of the water cycle (Brown 2000; Yang et al., 2003; Zhou and Li 2003; Tong and Velicogna 2010). In additionally, the glaciers affect the region's soil characteristics, plant composition, and plant communities (Darmody et al., 2004; Löffler 2005). At the local level, snow cover affects several soil parameters such as infiltration, temperature, humidity, microorganisms, and adsorption of carbon (Monson et al., 2006, Isard et al., 2007) Lu et al., (2005) depending on the extreme heat and thermal conductivity of the biological, chemical and geological processes. Miller (1998) is a valuable physical process that promotes soil infiltration to rehabilitate grass plants and other natural plants. So that, the glaciers are important for sustainable use of watersheds and hydrological cycles, as well as for planning and mitigation of associated disasters.

Melting glaciers are early indicators of climate change unlike the response of the forests which is slower and takes place over a long period of time. Since the middle of the last century, the global climate is changing drastically and as a result the current climate experiences more frequent extreme in Mongolia causing big losses amongst animal and land degradation. Impacts on glaciers and water resource management have been changing through climate changes in Mongolia territory characterized by dry and semi-arid climate with low precipitation Mongolia is harsh climate country which is long lasting cold winter, short and hot summer (high temperature variability: $-35^{\circ} \mathrm{C}$ in winter, $+35^{\circ} \mathrm{C}$ in summer)

The climate in the northern and western mountain area of the country is extremely cold, in winter the temperature can reach $50^{\circ} \mathrm{C}$ extreme continental climates with low precipitation, 85$90 \%$ of which fall in summer as rain. During the past years annual air temperature increased an average by $1.9^{\circ} \mathrm{C}$ in Mongolia.
Winter warming is more in the high mountain regions (3.0$4.5^{\circ} \mathrm{C}$ ), and less in the steppe and Gobi and desert $\left(1.0-2.0^{\circ} \mathrm{C}\right)$. Mongolia is high mountain land that has including glacier are located Khuiten and Altai Tavan Bogd summit of Mongol Altai mountainous areas which has chilly and breeze climate. One of the biggest river is located at the Mongol Altai mountainous areas which is named by Potanin river's area is 53.5 square kilometers. The researchers of mountain glaciers highlight that there is still little scientific information about the modern glaciers of arid areas of southeastern Altai and northwestern Mongolia and their dynamics, even in the World Glacier Inventory or in the database of the US National Snow and Ice Data Center (Ganiuskin et.al 2015). Moreover, they noted that some data have been published based mostly on satellite imagery and topographic maps (Yabouki and Ohata 2009; Khrutshy and Golubeva 2008; Chistyakov et al. 2011; Kamp et al. 2013a, b; Lehmkuhl 2012; Davaa and Kadota 2009), but the number and area of the glaciers of the same centers are different due to different methods used and different quality of imagery and maps.

The paper has not coverage by Mongolian all territory but those research is just particle or small study area. The study not covered by the Western Mongolia and just some peak of mountainous areas. Because all areas study is limited by financial support and geography location is far from capital. Therefore, this studies one purpose is used remote sensing technology and application such as satellite images, LANDSAT imagery, to identify area of glacier, using snow index such as normalized difference snow index (NDSI), its change in the last 45 years and volume of Ikh Turgen Mountain, which is a part of Altai Mountain, Western Mongolia. Moreover, the study explores to the reasons of the glacier change, correlation with the local weather station data and climate information.

\section{STUDY AREA}

The study area, Ikh Turgen mountain where located in NogoonNuur soum, Bayar-Ulgii aimag of Mongolia, and with border Russia. The Ikh Turgen mountain is situated within one of higher mountain system which approximately 4029-meter of see level 


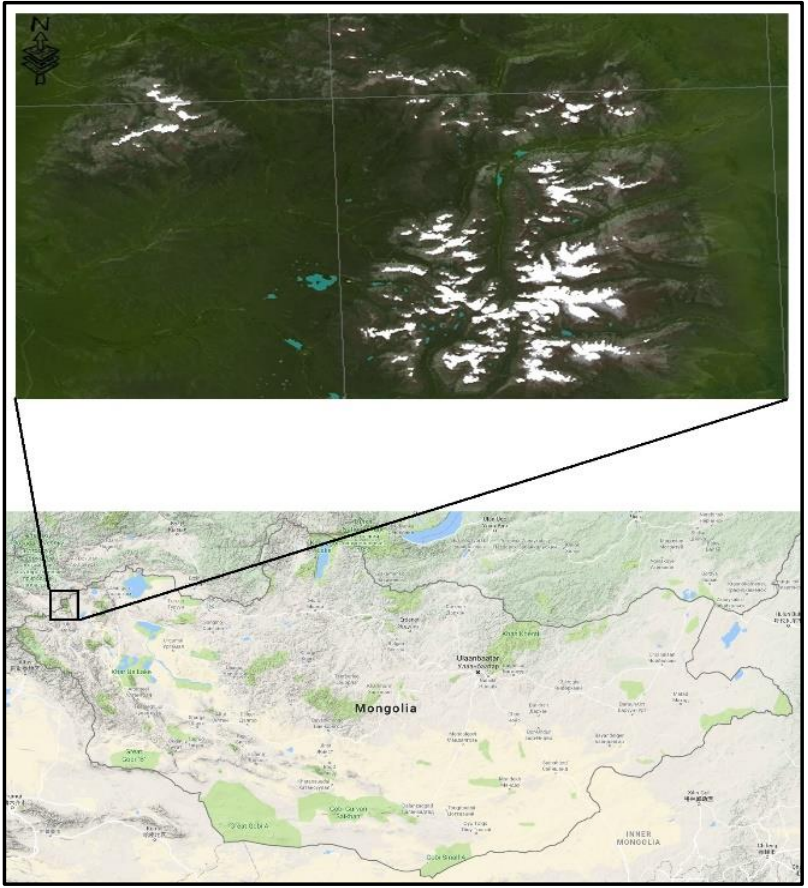

Figure 1. The Ikh Turgen mountain glacier in study area

The study area of glacier is located between $89^{\circ} 8^{\prime} 7 " \mathrm{E}, 50^{\circ} 5^{\prime} 43^{\prime \prime} \mathrm{N}$ (right top corner) and $90^{\circ} 0^{\prime} 7 . " \mathrm{E}, 49^{\circ} 41^{\prime} 43^{\prime \prime} \mathrm{N}$ (left bottom corner).

\section{MATERIALS AND METHODS}

\subsection{Satellite data}

So that we investigate the history of LANDSAT mission imagery includes: Multispectral Scanner (MSS), Thematic Mapper (TM), Enhanced Thematic Mapper (ETM+) and Operation Land Imager (OLC) sensors were acquired from 1972 to 2016, and (June, July, August and September) for path of MSS 154 war 025, TM, ETM+ and OLC were path 142, path 143 raw 025 , respectively. Therefore, in order to reduce scene to scene variation associated to sun angle, differences in atmospheric effects.

In general, we were collected minimal of cloud cover images in all scenes. Moreover, procced to the digital number values which were converted to radiance, and ground reflectance translated from radiance used the $6 \mathrm{~S}$ algorithm (Vermote et al. 1997). These data were obtained from United States Geological Survey (USGS) Global Visualization (Glovis):

https://glovis.usgs.gov/app?fullscreen $=0$ In addition, we were collected totally 26 scenes with time series imagery which is started 1975.06.14, 1976.08.19, 1977.09.01, 1977.09.19, 1989.09.19, 1991.09.26, 1992.06.08, 1993.09.22, 1994.08.24, 1995.07.03, 1997.08.25, 1998.08.20, 2000.09.10, 2001.09.04, 2002.07.06, 2002.08.07, 2003.09.18, 2008.08.30, 2010.08.04, 2010.08.20, 2011.07.06, 2011.08.07, 2013.09.06, 2014.08.31, 2015.08.02 and 2016.08.20 that covered from June to September. Finally, the study was used 19 scene of Landsat imagery of 41 years.

\subsection{Meteorological data}

The international 70 observation meteorological stations are registered in World Meteorological Organization (Eckert et al. 2015). Currently there 130 regional meteorological stations, 186 meteorological posts in observation network under the National Agency for Meteorology, Hydrology and Environment Monitoring of Mongolia (NAMHEM) Therefore, we were selected to nearest one meteorological station which named Nogoon-Nuur station. In addition, we were derived two main parameter of climate data such as the precipitation and air temperature data from 1985 to 2015 obtained from the division of database and archive of NAMHEM.

\subsection{Method}

In this study, we were used the one decision support tool which applied the decision tree approach by extracted potential glacier area. Some researchers have been applied previously to remotely sensed image (Michaelson et al. 1994, Hansen et al. 1996). Therefore, the decision trees have predicted class membership by recursively partitioning a database into more homogeneous subset-subgroup, moreover a different kind of variables and classifies is the used to classify the subset within continue subgroups and have grown tree could be selectively pruned followed by decision rules to produce more stable predictions of class membership (De Fries et al. 1998). The calculation of classify analysis in order to use NDSI $>0.40$ value of criteria for glacier area. It is computed by following Equation $(1,2)$

$D=D_{s}-D_{t}-D_{u}$

$D_{i}=-2 \sum_{k} n_{i k} \log P_{i k}$

Where, $n_{i k}$ is the number of cases of class $k$ in node $i$ and $P_{i k}$ is the probability distribution of class $k$ in node $i$, calculated as $n_{i k} / n_{i k}$ is described that (Venables and Ripley 1994).

In order to estimate the Normalized Differences Snow Index (NDSI) is calculated the following Equation (3)

$N D S I=\frac{\text { Green }-S W I R}{\text { Green }+S W I R}$

Where, Green is $0.545-0.565 \mathrm{~nm}$, SWIR is $1.547-1.749 \mathrm{~nm}$ of wavelength. Therefore, some researchers were as strongly suggested that by Hall et all., (1995), Xiao et al., (2002) and Kulkarni et al., (2006), which have been used a NDSI criteria of greater than 0.40 value to highlight the current of glacier. Also, as founded by Kulkarni et al., (2006) and Xiao et al., (2002) a near-infrared reflectance value is greater than 0.11 value was purposed to mask outing water pixels so that it has improve to NDSI classification accuracy.

\section{RESULTS AND DISCUSSIONS}

Global climate change has been a seriously and lasting impact on the environmental (Stocker et al. 2013) the potential of glacier and ice influenced by global warming has attracted a some of researchers focused, from the global frame to specific glaciers mountain (Jacob et al. 2012) Figures 2 and 3 shows that a long term of precipitation and air temperature were demonstrated over in study area which obtain Nogoon-Nuur meteorological station from 1989 to 2015 .

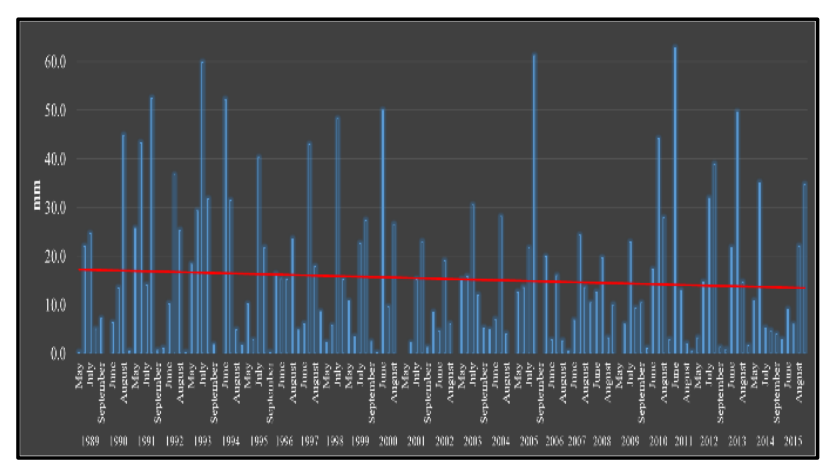

Figure 2. A long term of precipitation in study area from 1989 to 2015 by monthly 
In figure 2, a long term of precipitation has been showing differently changed in that period. Particularly, in 1990-2013 the rainfall was extremely high in June by an approximate reached to $63 \mathrm{~mm}$ of precipitation, on the other hand, less than $10 \mathrm{~mm}$ of value was in May and September over the period.

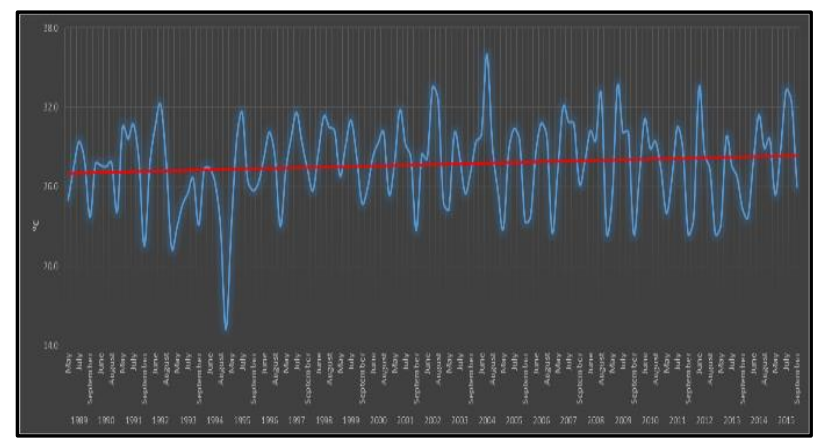

Figure 3. A long term of air temperature in study area from 1989 to 2015 by monthly

In figure 3, the graphic illustrated that air temperature staidly decreased in over period. Moreover, 1992, 1995, 1997, 2001, 2002, 2004, 2007-2009, 2012 and 2015 were highlighted to extremely hot period by maximum air temperature reached to 36.0 Celsius, which in 2004. Therefore, these were as well as highly related to melting glaciers. The potential 2D and 3D area were showing in figure 4 .

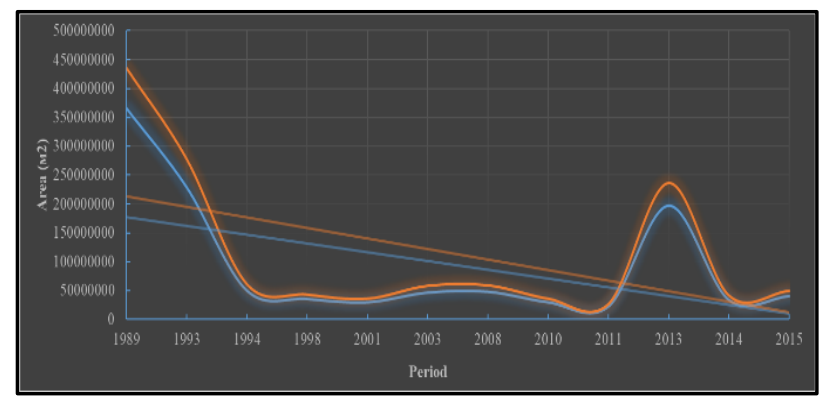

Figure 4. The potential 2D and 3D surface area of study site

In figure 4, a trend of potential 2D and 3D surface area have been showing in this study site. In general, in 1989-1994 the both glacier area was rapidly decreased by from a about $440,000,000$ square meters to $61,000,000$ square meters of glacier (figure $5 \mathrm{a}-$ $5 \mathrm{c}$ ), and after that this curve slightly decreasing up to 2001 (figure 5e), and between 2001-2008 gradually increased reach to around $58,000,000$ square meters (figure 5e-51). However, in 2011-2014 (figure $5 n-5 p$ ), were sharp grew might be seasonal snow influence to area extend. The potential area of Glacier has been showing in figure $5 \mathrm{a}-5 \mathrm{q}$ which are from 1989 to 2015 in study site.

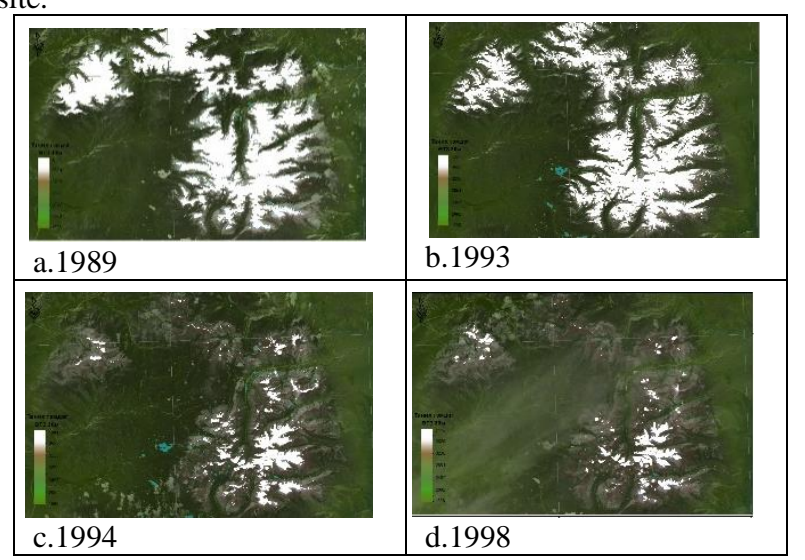

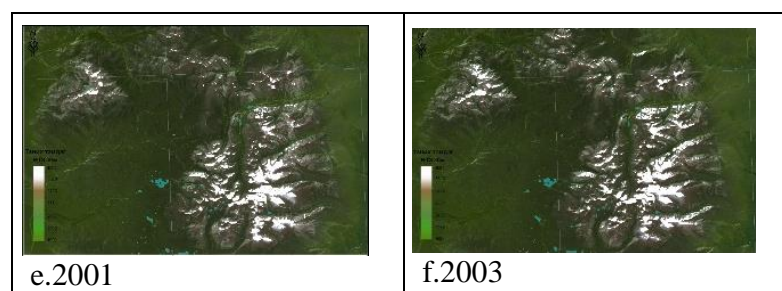
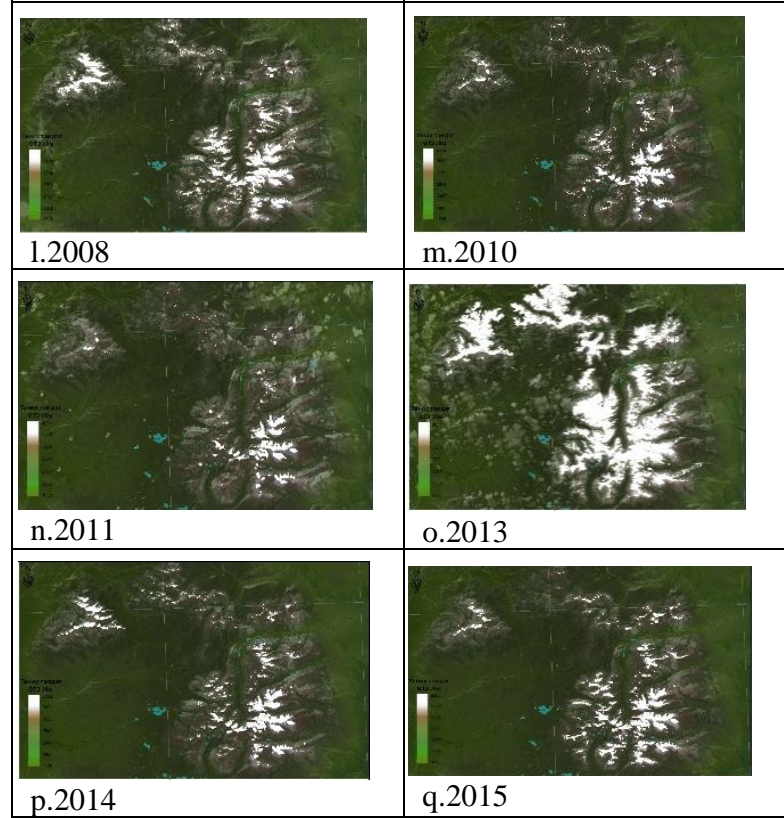

Figure 5. The potential area of Glacier in Study site

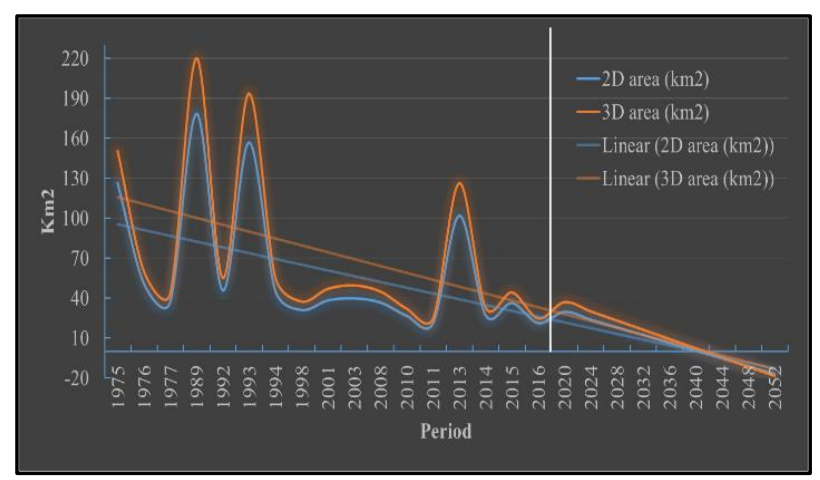

Figure 6. The forecasted potential glacier area of Ikh Turgen Mountain from 1975 to 2052

In figure 6 , the forecast of potential glacier area has been demonstrating in study area. In addition, in 2016-2040 the 3D surface area that will be exponentially decline up to 3 square kilometers.

\section{Conclusions}

There are several main results of our work that should be mentioned. First, despite the unfavorable climatic conditions the area of research has sufficient glaciation, but information about it is mostly old and some its features are still poorly studied, especially mass balance and dynamics of the glaciers. We tried to update glacier area using time series imagery of Landsat satellite. Second, the past years, there was a dramatic alters of the glaciers, and local mechanisms such as debris-coverage of the glacial related with local weather conditions and the climate changes. Third: in the last 20 years there is a continuous trend to glacial retreat and the glaciers of the potential area predicted the future in Western Mongolia. The tendency of some slowing down 
of glacial slightly decreased retreat in the future. Still it is quite possible that it is just a short climatic fluctuation like the one that was observed in 1993 and 2012, when some glaciers snouts joint icings and visually advanced several dozen meters, though the next years the retreat continued.

Difference between different results of remote sensing shows the necessity of combination of remote sensing methods with different direct methods of observations and monitoring. This gives us the opportunity to improve our results by continuing field work in our current in situ polygons, as well as to establish an observations network in some poorly studied centres of glaciation of Western Mongolia.

\section{ACKNOWLEDGEMENTS}

The researchers would like to thank the United States Geological Survey (USGS) Global Visualization Viewer (GloVis) and National Remote Sensing Center (NRSC) of Mongolia for providing raw data and research work.

\section{REFERENCES}

Stocker, T. F., Qin, D., Plattner, G. K., Tignor, M., Allen, S. K., Boschung, J., \& Midgley, P. M. (2013). Climate change 2013: the physical science basis. Intergovernmental panel on climate change, working group I contribution to the IPCC fifth assessment report (AR5). New York.

Jacob, T., Wahr, J., Pfeffer, W. T., \& Swenson, S. (2012). Recent contributions of glaciers and ice caps to sea level rise. Nature, 482(7386), 514.

Beniston, M (2003) Climatic change in mountain regions: a review of possible impacts. Climatic Change, 59, 5-31

Kulkarni, A. V., Singh, S. K., Mathur, P., \& Mishra, V. D. (2006). Algorithm to monitor snow cover using AWiFS data of RESOURCESAT-1 for the Himalayan region. International Journal of Remote Sensing, 27(12), 2449-2457.

Xiao, X., Moore Iii, B., Qin, X., Shen, Z., \& Boles, S. (2002). Large-scale observations of alpine snow and ice cover in Asia: using multi-temporal VEGETATION sensor data. International Journal of Remote Sensing, 23(11), 2213-2228.

Hall, D. K., Foster, J. L., Chien, J. Y., \& Riggs, G. A. (1995). Determination of actual snow-covered area using Landsat TM and digital elevation model data in Glacier National Park, Montana. Polar Record, 31(177), 191-198.

Ripley, B. D., \& Venables, W. N. (1994). Modern applied statistics with S-Plus. Springer-Verlag.

Michaelsen, J., Schimel, D. S., Friedl, M. A., Davis, F. W., \& Dubayah, R. C. (1994). Regression tree analysis of satellite and terrain data to guide vegetation sampling and surveys. Journal of Vegetation Science, 5(5), 673-686.

ansen, M., Dubayah, R., \& DeFries, R. (1996). Classification trees: an alternative to traditional land cover classifiers. International journal of remote sensing, 17(5), 10751081.

De Fries, R. S., Hansen, M., Townshend, J. R. G., \& Sohlberg, R. (1998). Global land cover classifications at $8 \mathrm{~km}$ spatial resolution: the use of training data derived from Landsat imagery in decision tree classifiers. International Journal of Remote Sensing, 19(16), 3141-3168.
Vermote, E.F., D. Tanre, J. L. Deuze, M. Herman, and J. Morcrette, J., 1997. "Second Simulation of the Satellite

Eckert, S., Hüsler, F., Liniger, H., \& Hodel, E. (2015). Trend analysis of MODIS NDVI time series for detecting land degradation and regeneration in Mongolia. Journal of Arid Environments, 113, 16-28. 